\title{
Ultrasound-guided glossopharyngeal nerve block via the styloid process for glossopharyngeal neuralgia: a retrospective study
}

This article was published in the following Dove Press journal: Journal of Pain Research

\author{
Qian Liu',* \\ Qing Zhong ${ }^{2, *}$ \\ Guoqiang Tang ${ }^{1, *}$ \\ Guanghong $\mathrm{He}^{\prime}$ \\ 'Department of Anesthesiology, First \\ People's Hospital, Zigong, Sichuan, \\ People's Republic of China; ${ }^{2}$ Department \\ of Anesthesiology, People's Hospital, \\ Jianyang, Sichuan, People's Republic of \\ China \\ *These authors contributed equally to \\ this work
}

Correspondence: Guoqiang Tang Department of Anesthesiology, First People's Hospital, No. 42 Shangyi Hao Road, Ziliujing District, Zigong, Sichuan 64300, People's Republic of China Email liuqianlqlqlqlalq@I63.com
Objective: To examine the effectiveness and safety of ultrasound-guided glossopharyngeal nerve block via the styloid process for primary glossopharyngeal neuralgia.

Methods: This retrospective study included all patients receiving glossopharyngeal nerve block via the styloid process under ultrasound guidance for primary glossopharyngeal neuralgia between January 2015 and May 2018 at our hospital. The primary outcome of the study was pain relief as assessed using the visual analog scale (VAS). Treatment was considered effective if the VAS score decreased by more than 2 points.

Results: Twelve patients were included in the analysis. The baseline VAS scores ranged from 5 to 9 . All patients received previous pharmacotherapy. Other previous treatments included pulsed mode radiofrequency $(n=4)$, microvascular decompression $(n=2)$, and glossopharyngeal nerve block (not under ultrasound guidance; $n=2$ ). The patients completed a total of 48 injections for glossopharyngeal nerve block. At discharge from the hospital, and at 6,12 , and 18 months thereafter, $10 / 12,10 / 12,7 / 12$, and $4 / 12$ patients achieved pain relief and the effective rate was $83.3 \%$ at discharge, $83.3 \%$ at 6 months, $58.3 \%$ at 1 year, and $33.3 \%$ at 18 months, respectively.

Conclusion: Ultrasound-guided glossopharyngeal nerve block via the styloid process is a safe, radiation-free, repeatable, convenient, and effective treatment. It can provide a treatment option for patients with glossopharyngeal neuralgia.

Keywords: ultrasound, glossopharyngeal neuralgia, styloid process, glossopharyngeal nerve block

\section{Introduction}

Glossopharyngeal neuralgia, also known as vagal glossopharyngeal neuralgia, is characterized by intermittent episodes of shooting sharp pain in the jaw, throat, tongue, and ear that fall within the sensory distribution of the glossopharyngeal nerve (cranial nerve IX). ${ }^{1,3,4,5}$ Its overall incidence is estimated to be between 0.2 and 0.7 cases per 100,000 person-years, which is much lower than that of trigeminal neuralgia (28.9 cases per 100,000 person-years). ${ }^{2}$ Pharmacotherapy with anticonvulsants, tricyclic antidepressants, and anti-inflammatory agents is effective in relieving paroxysmal pain in most glossopharyngeal neuralgia patients, ${ }^{1,3-7}$ but drug toxicities such as rash, diplopia, cognitive decline, decreased blood cell count, or liver dysfunction limit their efficacy.

Interventional and surgical options, such as gamma knife radiation, surgical dissection, microvascular decompression or electrical stimulation of the motor cortex 
contralateral to the pain area, are needed when conservative pharmacotherapy fails. ${ }^{8-12,15,22,23,27}$ Glossopharyngeal nerve block provides transitory cessation of nerve impulse conduction for relief of glossopharyngeal neuralgia via injection of local anesthetic and steroids and is usually well tolerated, and it is not associated with serious adverse effects. ${ }^{13,16,17,21}$ The nerve block is commonly performed by four different routes: topical application, intraoral injection, ${ }^{26}$ parapharyngeal space injection, and percutaneous peristyloid injection. ${ }^{13-15}$ However, all these routes have limitations. Because of the large number of bone structures around the glossopharyngeal nerve, the puncture needle is positioned under fluoroscopic guidance during percutaneous peristyloid injection, and contrast media is injected to confirm the extent of drug diffusion and whether the blood vessels are violated. Consequently, the procedure is very inconvenient during operation.

Meanwhile, dependence on bone structure poses a great challenge to operators in localization and radiography. ${ }^{20,28}$ Ultrasound can visualize bone, soft tissue, and peripheral blood vessels in real time and directly observe the diffusion of drugs, effectively avoiding important structures such as blood vessels, and reducing the occurrence of complications. Ultrasound-guided nerve block is becoming increasingly popular among anesthesiologists and pain physicians, and ultrasound-guided glossopharyngeal nerve block has also been reported in some cases. ${ }^{14,16,17,28-31}$

In the current study, we investigated the efficacy and safety of ultrasound-guided glossopharyngeal nerve block via the styloid process in 12 patients with primary glossopharyngeal neuralgia who failed previous therapies.

\section{Patients and methods}

\section{Patients}

This retrospective study included patients with primary glossopharyngeal neuralgia who received pain care between January 2015 and May 2018 at the Department of Pain Medicine, Department of Neurology, and Department of Neurosurgery of First People's Hospital, Zigong, Sichuan, China. Primary glossopharyngeal neuralgia was diagnosed according to the International Headache Society diagnostic criteria., ${ }^{1,3}$ Major inclusion criteria were 1) patients were diagnosed with primary glossopharyngeal neuralgia; 2) patients were aged between 18 and 85 years; 3) patients who failed pharmacotherapy or other treatments. Major exclusion criteria were 1) patients with severe cardiopulmonary diseases such as myocardial infarction, and heart failure; 2) patients who had styloid truncation ipsilateral to the side of the disease; 3 ) patients with mental disorders, local infection, or pregnancy; 4) patients with abnormal coagulation function; 5) patients with local anesthetic allergy.

The study protocol was approved by the local ethics committees of the authors' affiliated institutions, and the study was performed in accordance with the Declaration of Helsinki. Patient consent was not required due to the retrospective nature of this study and because available data were collected through outpatient department and telephone. In the current report, patient data were anonymized.

\section{Ultrasound-guided glossopharyngeal nerve block}

The patient was placed in the lateral position with a thin pillow under the head. The area over the mastoid process was scanned using a low-frequency convex array probe to locate the mastoid and the mandibular angle, and a line (M1) was drawn between the two landmarks. Another line was drawn from $1.5 \mathrm{~cm}$ above the posterior edge of the mandibular angle to the mastoid (M2) (Figure 1A). The convex array probe was placed on M2 to visualize the styloid process (Figure 1B). The scanning sequence was parallel to M2, moving up and down to find the clearest image of the styloid process (Figure 1C). Subsequently, color flow Doppler was used to identify the internal carotid artery and the internal vein mixed blood flow signals below or behind the styloid process (Figure 1D). A 22-gauge and 3.5-inch needle was directed for ultrasound-guided lateral puncture of the mandible in plane. When the needle tip reached the styloid process, it was slid through the styloid process to the back of the styloid process, and the needle path is depicted in Figure 1C. When no blood or cerebrospinal fluid appeared after careful withdrawal the needle, $0.5 \%$ lidocaine and $40 \mathrm{mg}$ methylprednisolone were slowly injected in $3 \mathrm{~mL}$ under real-time ultrasound guidance. The patient was observed for $30 \mathrm{mins}$ before returning to the ward. Considering the accuracy of ultrasound is different from that of CT and that it is expected to achieve an enhanced and lasting effect, patients received an injection once every other day, for a total of four times for duration of 9 days. $^{36-40}$ The procedure was performed by the same physician.

\section{Patient evaluation}

We retrieved the following data from the hospital's electronic record systems including patient demographics, 

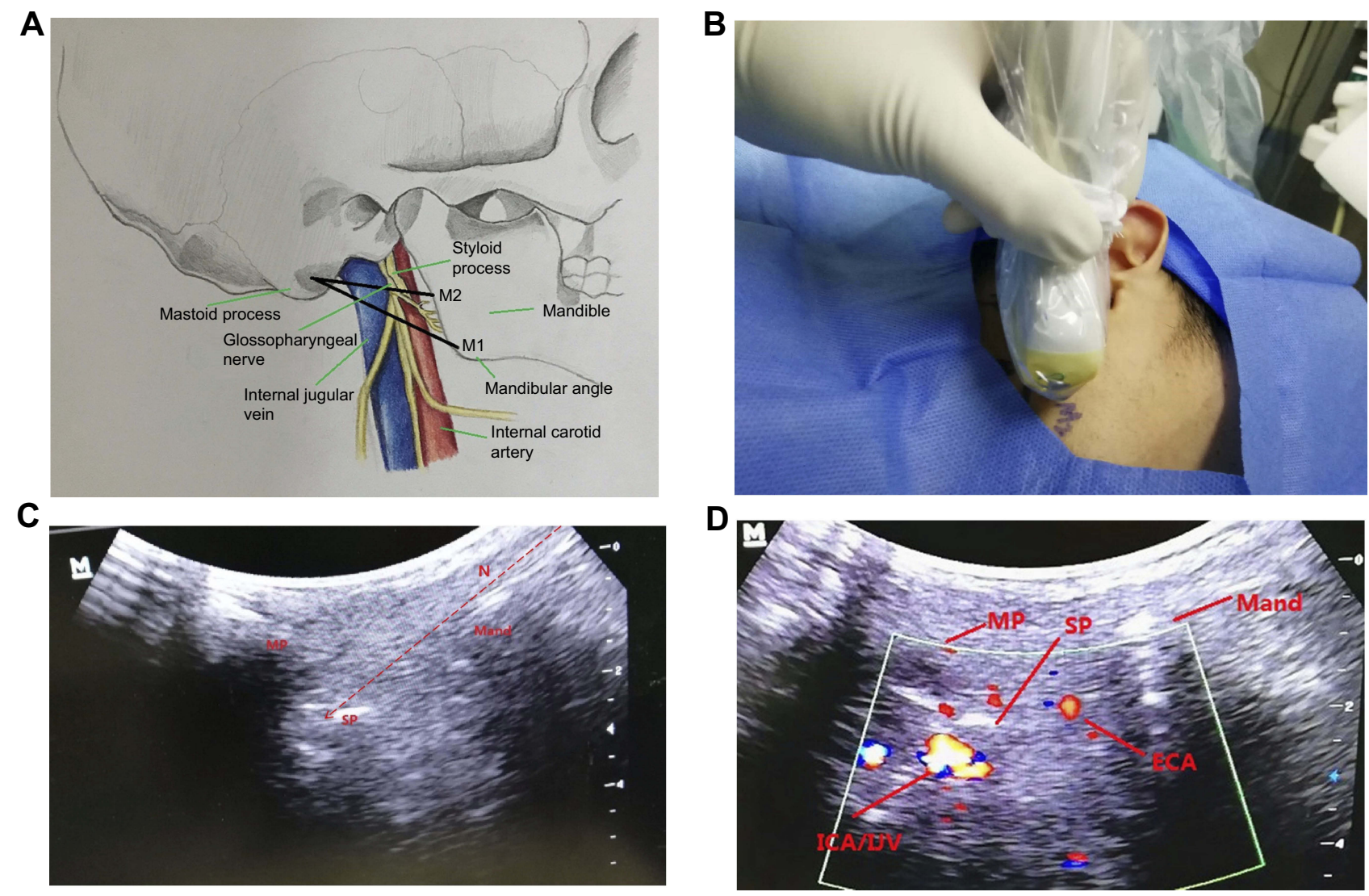

Figure I (A) The body surface location map: a line (MI) is drawn between the mastoid process and the mandibular angle. Another line is drawn from I.5 cm above the posterior edge of the mandibular angle to the mastoid process (M2). The posterior part of the styloid process is adjacent to the internal carotid artery and internal jugular vein, and the glossopharyngeal nerve is located on the superficial surface of the internal carotid artery and vein. (B) M2 is the plane of ultrasonic probe. (C) The ultrasound image represents the sagittal view. The right side of the image shows the depth of investigation. The left side of the image is the mastoid process, the right side of the image is the mandible, the styloid process between the two sides is clearly visible on the image, and the arrow with dashed lines indicates puncture path. (D) Color flow Doppler shows a clear blood flow signal. The external carotid artery is close to the mandible, and the mixed blood flow signals located below or behind the styloid process are the internal carotid artery and the internal jugular vein. The styloid process is an important reference point in the process of puncture.

Abbreviations: MP, mastoid process; SP, styloid process; Mand, mandible; N, puncture path; ICA, internal carotid artery; IJV, internal jugular vein; ECA, external carotid artery.

onset, duration, intensity, and location of pain, predisposing factors of pain, and previous pharmacological and surgical interventions. The patients were followed up by telephone or outpatient visits every three months after nerve block treatment. Pain was evaluated using a 10point visual analog scale (VAS). The primary outcome of the study was pain relief upon discharge from the hospital, and at 6,12 , and 18 months thereafter. A 2-point reduction in VAS scores was considered to be an effective treatment. ${ }^{33-35}$ The effective rate was the percentage of patients with greater than 2-point reduction in VAS scores. The total maintenance time was calculated from the date of the last session of glossopharyngeal nerve block treatment to the date of recovery or aggravation of pain. When pain levels or VAS scores reached pre-treatment levels, the study and follow-up were terminated. In addition, complications were recorded.

\section{Results}

\section{Patient demographic and baseline characteristics}

Because of the low incidence of glossopharyngeal neuralgia, we only found a total of 14 patients with glossopharyngeal neuralgia who received pain care during the study period. One patient was excluded because of myocardial infarction and one patient was excluded due to glossopharyngeal neuralgia caused by tumor compression. Finally, 12 patients who received glossopharyngeal nerve block were included in the analysis. Patient demographic and baseline characteristics are shown in Table 1. Their median age was 64 years (range 43-83 years). The median duration of pain was 1.5 years (range 3 months to $>11$ years) and their median VAS score was 7 (range 5-9). All patients received previous pharmacotherapy. Other previous treatments 
Table I Patient demographic, baseline, and treatment characteristics

\begin{tabular}{|c|c|c|c|c|c|}
\hline $\begin{array}{l}\text { Patient } \\
\text { no. }\end{array}$ & Age(years)/sex & $\begin{array}{l}\text { Duration of symptoms } \\
\text { prior to injection }\end{array}$ & $\begin{array}{l}\text { Previous surgeries/ } \\
\text { interventions }\end{array}$ & Medications & VAS \\
\hline 1 & $5 I / M$ & 7 months & None & Carbamazepine & 5 \\
\hline 2 & $52 / M$ & $>1$ year & None & $\begin{array}{l}\text { Carbamazepine, aminophenol- } \\
\text { hydroxycodone }\end{array}$ & 7 \\
\hline 3 & $65 / M$ & $>1$ year & None & Gabapentin & 7 \\
\hline 4 & $43 / \mathrm{F}$ & 3 months & None & $\begin{array}{l}\text { Carbamazepine, fentanyl patch, } \\
\text { gabapentin }\end{array}$ & 6 \\
\hline 5 & $83 / F$ & $>1$ year & None & Carbamazepine, tramadol & 6 \\
\hline 6 & $61 / M$ & I year & None & Oxcarbazepine, duloxetine & 8 \\
\hline 7 & $8 \mathrm{I} / \mathrm{F}$ & $>11$ years & CT-guided GNB & Carbamazepine, pregabalin & 6 \\
\hline 8 & $70 / F$ & $>3$ years & $\begin{array}{l}\text { Fluoroscopy-guided GNB, pulsed } \\
\text { mode radiofrequency }\end{array}$ & $\begin{array}{l}\text { Carbamazepine, aminophenol- } \\
\text { hydroxycodone, gabapentin }\end{array}$ & 7 \\
\hline 9 & $63 / M$ & $>2$ years & Pulsed mode radiofrequency & $\begin{array}{l}\text { Carbamazepine, aminophenol- } \\
\text { hydroxycodone }\end{array}$ & 7 \\
\hline 10 & $79 / \mathrm{F}$ & $>10$ years & $2 \times$ Pulsed mode radiofrequency & $\begin{array}{l}\text { Carbamazepine, pregabalin, } \\
\text { hydrocodone }\end{array}$ & 9 \\
\hline 11 & $52 / \mathrm{F}$ & $>2$ years & $\begin{array}{l}\text { Microvascular decompression, } \\
\text { Pulsed mode radiofrequency }\end{array}$ & $\begin{array}{l}\text { Carbamazepine, morphine sulfate, } \\
\text { tramadol, duloxetine }\end{array}$ & 9 \\
\hline 12 & $71 / M$ & $>3$ years & Microvascular decompression & $\begin{array}{l}\text { Oxcarbazepine, duloxetine, } \\
\text { oxycontin }\end{array}$ & 8 \\
\hline
\end{tabular}

Abbreviations: GNB, glossopharyngeal nerve block; VAS, visual analog scale.

included radiofrequency ablation $(\mathrm{n}=4)$, microvascular decompression $(\mathrm{n}=2)$, and received glossopharyngeal nerve block $(\mathrm{n}=2)$.

\section{Primary outcome}

Twelve patients completed a total of 48 injections for glossopharyngeal nerve block. The mean procedure time was 9.51 \pm 0.89 mins (range $7-12$ mins). All patients reported pain relief within 10 mins of the injection. The median follow-up duration after glossopharyngeal nerve block was 16.5 months (range 0-24 months). At discharge, and 6, 12, and 18 months thereafter, $10 / 12,10 / 12,7 / 12$, and $4 / 12$ patients achieved pain relief (Table 2 and Figure 2). The effective rate was $83.3 \%$ at discharge, $83.3 \%$ at 6 months, $58.3 \%$ at 1 year, and $33.3 \%$ at 18 months, respectively. The median mitigation time was 13.5 months (range 0-24 months). After treatment, the drug was not reduced when the patients were discharged from the hospital. During the follow-up, pain in 1/12 patient was not relieved after treatment, and the dose of drug treatment was increased until microvascular decompression was performed.
In the remission stage, the maximum reduction in drug use was one third in $4 / 12$ patients, one half in $4 / 12$ patients, three fourths in 2/12 patients, and well controlled in 1/12 patient who had not taken drug.

\section{Complications}

One patient developed panic, dizziness, and nodal tachycardia (heart rates $110-120 / \mathrm{min}$ ) during the treatment and the symptoms were gradually relieved after intravenous injection of esmolol $(20 \mathrm{mg})$. One patient suffered from dysphagia in the throat and one patient had hoarseness, all the patients returned to normal after $1 \mathrm{hr}$ of observation. No significant adverse reactions occurred in other patients during the course of treatment.

\section{Discussion}

At present, the pathogenesis of primary glossopharyngeal neuralgia is not clear. It is believed that benign peripheral stimulation or injury of cranial nerve IX is the culprit, ${ }^{18,19}$ which provides a basis for the treatment of glossopharyngeal 
Table 2 Efficacy of glossopharyngeal nerve block for patients with glossopharyngeal nerve neuralgia

\begin{tabular}{|l|l|l|l|l|l|l|l|l|l|l|}
\hline $\begin{array}{l}\text { No. } \\
\text { of } \\
\text { cases }\end{array}$ & $\begin{array}{l}\text { Follow-up } \\
\text { duration, } \\
\text { months }\end{array}$ & \multicolumn{6}{|l|}{ No. of patients whose VAS scores decreased by more than 2} & $\begin{array}{l}\text { Mitigation } \\
\text { time, } \\
\text { months }\end{array}$ & $\begin{array}{l}\text { Mean } \\
\text { procedure } \\
\text { time, mins }\end{array}$ \\
\hline 12 & $3-24$ & $\begin{array}{l}\text { Discharge } \\
10\end{array}$ & $\begin{array}{l}3 \text { months } \\
11\end{array}$ & $\begin{array}{l}6 \text { months } \\
10\end{array}$ & $\begin{array}{l}9 \text { months } \\
10\end{array}$ & $\begin{array}{l}12 \text { months } \\
7\end{array}$ & $\begin{array}{l}15 \text { months } \\
6\end{array}$ & $\begin{array}{l}18 \text { months } \\
4\end{array}$ & \\
\hline \multicolumn{2}{|l|}{ Effective rate (\%) } & 83.3 & 91.6 & 83.3 & 83.3 & 58.3 & 41.6 & 33.3 & $\begin{array}{l}\text { Median 13.5 } \\
\text { (range 0-24) }\end{array}$ & $\begin{array}{l}9.51 \pm 0.89 \\
\text { mins }\end{array}$ \\
\hline
\end{tabular}

Abbreviation: VAS, visual analog scale.

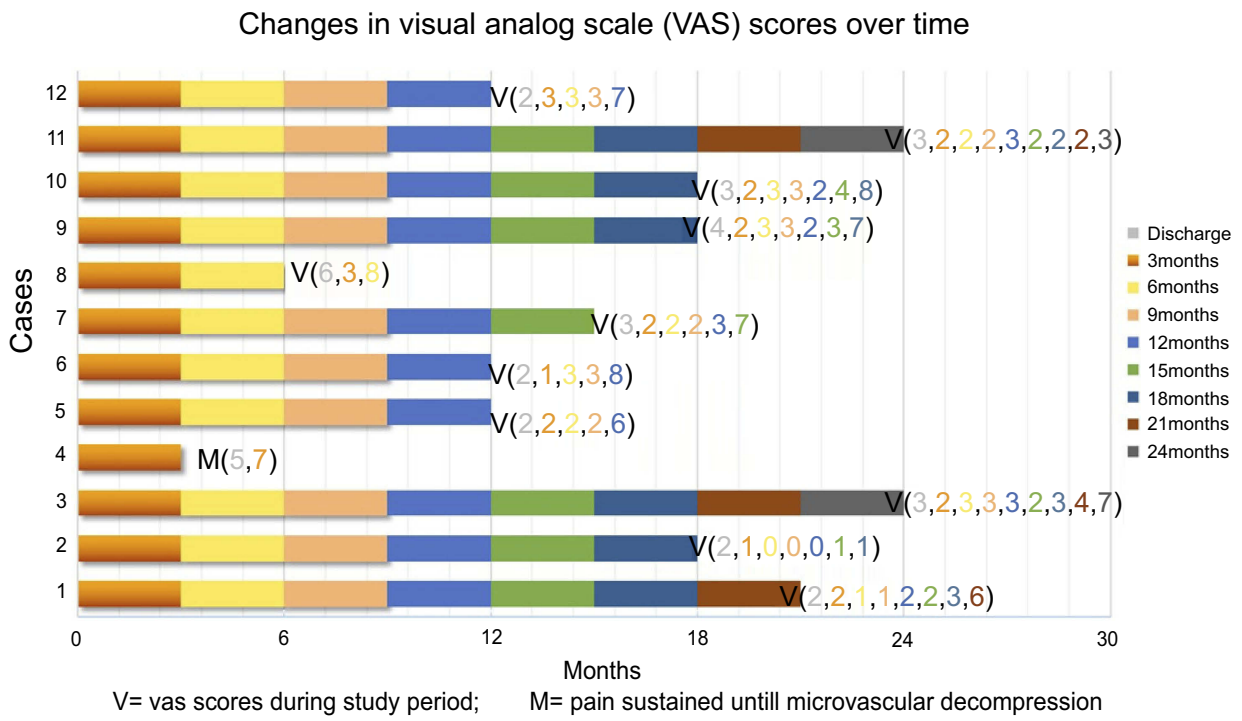

Figure $2 \mathrm{~A}$ bar graph shows the changes in visual analog scale (VAS) scores over the time for 12 patients. The color coding scores correspond to the VAS scores reported by the patient at the follow-up intervals.

neuralgia by blocking nerve conductions of the glossopharyngeal nerve. The current study demonstrated that ultrasound-guided glossopharyngeal nerve block via the styloid process was safe and effective for the majority of glossopharyngeal neuralgia patients over 6 months, but only a small proportion of the patients at 18 months.

There are three main methods of ultrasound-guided block of the glossopharyngeal nerve at present. The first method is guided by ultrasound to block the parapharyngeal space of the distal branch of the glossopharyngeal nerve. ${ }^{14}$ The second method is ultrasound-guided longitudinal axis cervical internal arteriovenous surface block. ${ }^{16}$ The third method is ultrasound-guided transverse axis block via the styloid process. The parapharyngeal space block of the distal branch of the glossopharyngeal nerve is far away from the internal carotid artery and vein, and the operative risk is obviously lower compared with the other two methods. ${ }^{14}$ However, the location of the block is lower than that of the glossopharyngeal nerve trunk, leading to diminished efficacy. The glossopharyngeal nerve trunk is located at the position of the styloid process or at the level of the internal carotid artery and vein, requiring a higher blocking position. Though nerve trunk block yields better efficacy than block at a nerve branch, it incurs greater risk of bleeding or local anesthetic side effects during puncture of superficial arteriovenous block through the longitudinal axis of the internal carotid artery and vein. ${ }^{16}$ It is prone to injury of the blood vessel and causes bleeding. Transaxial styloid process block with the styloid process as a puncture target may greatly lower the risk of vessel injuries as the tip position can be adjusted along the posterior styloid process after reaching the styloid process. This method is effective in the treatment of glossopharyngeal neuralgia and also in the treatment of neuralgia caused by the styloid process syndrome, local scar, and fibrotic compression of the styloid process. ${ }^{16,24,25}$ Therefore, we think that the transverse axis block of the glossopharyngeal nerve via the styloid pathway is superior to the first two methods under ultrasound guidance. 
Although x-ray-based guidance is still considered in diagnostic and interventional procedures for head and neck blocks, ${ }^{10,11,15,21,22}$ our study showed that ultrasound-guided glossopharyngeal nerve block can be carried out repeatedly. The styloid is located between the mastoid process and the mandible; therefore, the acoustic window is very small, and the styloid can be easily obscured by bones. In the current study, the convex array probe was used as the linear ultrasonic probe requires a large contact surface, consequently a large acoustic window, to effectively pass the sound beam through the target. On the other hand, the convex array probe scans in arc; therefore, the lower part of the bone can be scanned readily and the near field of vision is large. Because the mastoid process, the styloid process, and the mandible are clearly visible with the use of convex array probe, and the internal carotid artery and vein below the styloid process can be clearly identified by color Doppler in the puncture plane, the risk of blood vessel injury, local anesthetic side effects and hematoma can be avoided during the puncture. At the same time, the range of drug diffusion can be observed dynamically under real-time ultrasound monitoring, and the needle position can be adjusted in time to improve the success rate of block. Compared with X-ray or CT operation, nerve block under ultrasonic guidance had a very short procedural time, taking 7-12 mins to complete. Furthermore, the operation of the ultrasound-guided glossopharyngeal nerve block is convenient to perform and cost-effective, and the operator and the patient can both avoid radiation exposure. This treatment has the advantages of convenience, short operative time, and effective treatment. The treatment approach can also be feasible at the outpatient department. However, due to the glossopharyngeal nerve block and abundant blood vessels and nerves around the styloid process, it is necessary to have good first aid equipment and strict monitoring. It is also worthy of noting that those who had been treated with radiofrequency ablation and microvascular decompression also achieved pain relief after block. As the time elapsed, the VAS score increased, pain relief was decreased, and the pain recovery rate increased in 9-15 months after treatment (Figure 2). However, after relapse, patients can still achieve long-term analgesia after repeated block treatments. In the future, we will investigate whether the use of long-acting steroids can prolong maintenance time.

\section{Limitations}

There are several limitations to the current study. The study is retrospective in nature and cannot establish causal relationships, as a result, the patient's inaccurate description of other treatments during the follow-up may have an impact on the outcome and we did not carry out a comparative study of glossopharyngeal nerve block accuracy between ultrasound-guided and CT or X-ray. Furthermore, because of the low incidence of glossopharyngeal neuralgia, the cohort is small in size and also lacks a control arm or a parallel comparison group. In addition, all the procedures were performed by a single operator. Therefore, our findings await confirmation by future randomized controlled studies with a larger sample size and longer follow-up duration.

\section{Conclusion}

In conclusion, ultrasound-guided glossopharyngeal nerve block via the styloid process is a safe, radiation-free, repeatable, convenient, and effective treatment. It can provide a treatment option for patients with glossopharyngeal neuralgia.

\section{Ethics approval and consent to participate}

The study was approved by the local ethics committee. The name of the ethics committee is Ethics Committee of the First People's Hospital, Zigong, China. As the study is a retrospective study, we mainly used available data collected through outpatient visits and telephone, so patient consent to review their medical records was waived by the Ethics Committee of the First People's Hospital. In order to protect the privacy of patients, we anonymized patient data in this report. The study was undertaken in strict accordance with the Declaration of Helsinki.

\section{Availability of data and materials}

The datasets used and/or analyzed during the current study are available from the corresponding author on reasonable request. All data generated or analyzed during this study are included in this published article.

\section{Acknowledgments}

The authors thank the patients who participated in this study. Qian Liu, Guoqiang Tang, and Qing Zhong should be regarded as co-first authors in this work. 


\section{Author contributions}

All authors contributed to data analysis, drafting and revising the article, gave final approval of the version to be published, and agree to be accountable for all aspects of the work.

\section{Disclosure}

The authors report no conflicts of interest in this work.

\section{References}

1. Blumenfeld A, Nikolskaya G. Glossopharyngeal neuralgia. Curr Pain Headache Rep. 2013;17(7):527-536. doi:10.1007/s11916013-0343-x

2. Manzoni GC, Torelli P. Epidemiology of typical and atypical craniofacial neuralgias. Neurol Sci. 2005;26(S2):s65-S67. doi:10.1007/ s10072-005-0410-0

3. Headache Classification Subcommittee of the International Headache Society. The international classification of headache disorders: 2nd edition. Cephalalgia. 2004;24(Suppl 1):9-160.

4. Reddy K, Hobson DE, Gomori A, Sutherland GR. Painless glossopharyngeal "Neuralgia" with syncope: a case report and literature review. Neurosurgery. 1987;21(6):916-919. doi:10.1227/00006123198712000-00023

5. Jamshidi A, Masroor MA. Glossopharyngeal neuralgia with cardiac syncope: treatment with a permanent cardiac pacemaker and carbamazepine. Arch Intern Med. 1976;136(7):843-845.

6. Fromm GH. Clinical pharmacology of drugs used to treat head and face pain. Neurol Clin. 1990;8(1):143-151.

7. Moretti R, Torre P, Antonello RM, Bava A. Gabapentin treatment of glossopharyngeal neuralgia: a follow-up of four years of a single case. Eur J Pain. 2002;6(5):403-407.

8. Patel A, Kassam A, Horowitz M, Chang YF. Microvascular decompression in the management of glossopharyngeal neuralgia: analysis of 217 cases. Neurosurgery. 2002;50(4):705-711. doi:10.1097/ 00006123-200204000-00004

9. Ferroli P, Fioravanti A, Schiariti M, Broggi G. Microvascular decompression for glossopharyngeal neuralgia: a long-term retrospective review of the Milan-Bologna experience in 31 consecutive cases. Acta Neurochir (Wien). 2009;151(10):1245-1250. doi:10.1007/ s00701-009-0330-5

10. Chua NH, Beems T, Vissers KC. Two cases of glossopharyngeal neuralgia successfully treated with pulsed radiofrequency treatment. Ann Acad Med Singapore. 2011;40(8):387-389.

11. Mollinedo FT, Esteban SL, Vega CG, et al. Pulsed radiofrequency treatment in a case of Eagle's syndrome. Pain Pract. 2013;13 (5):399-404. doi:10.1111/j.1533-2500.2012.00592.x

12. Borius PY, Tuleasca C, Muraciole X, et al. Gamma knife radiosurgery for glossopharyngeal neuralgia: a study of 21 patients with longterm follow-up. Cephalalgia. 2018;38(3):543-550. doi:10.1177/ 0333102417698961

13. Funasaka S, Kodera K. A new method of treatment for glossopharyngeal neuralgia-intraoral nerve block (author's transl). Nihon Jibiinkoka Gakkai Kaiho. 1977;80(9):902-906.

14. Ažman J, Stopar Pintaric T, Cvetko E, Vlassakov K. Ultrasoundguided glossopharyngeal nerve block: a cadaver and a volunteer sonoanatomy study. Reg Anesth Pain Med. 2017;42(2):252-258. doi:10.1097/AAP.0000000000000561

15. Telischak NA, Heit JJ, Campos LW, et al. Fluoroscopic C-arm and CT-guided selective radiofrequency ablation for trigeminal and glossopharyngeal facial pain syndromes. Pain Med. 2018;19(1):130-141. doi: $10.1093 / \mathrm{pm} / \mathrm{pnx} 088$
16. Bedder MD, Lindsay D. Glossopharyngeal nerve block using ultrasound guidance: a case report of a new technique. Reg Anesth. 1989;14(6):304-307.

17. Maher T, Shankar H. Ultrasound-guided peristyloid steroid injection for eagle syndrome. Pain Pract. 2017;17(4):554-557. doi:10.1111/ papr.12497

18. Shereen R, Gardner B, Altafulla J, et al. Pediatric glossopharyngeal neuralgia: a comprehensive review. Childs Nerv Syst. 2018. doi:10.1007/s00381-018-3995-3

19. Dubey A, Mujoo S, Sakarde SB, Dubey AK. Paroxysmal neuralgia in pediatric population-a diagnostic dilemma for physicians and dental practioners. Kathmandu Univ Med J (KUMJ). 2012;10(40):74-77.

20. Prades JM, Gavid M, Asanau A, et al. Surgical anatomy of the styloid muscles and the extracranial glossopharyngeal nerve. Surg Radiol Anat. 2014;36:141-146. doi:10.1007/s00276-013-1162-9

21. Schuster NM, Hsia-Kiung ME. Glossopharyngeal postherpetic neuralgia palliated with fluoroscopic-guided nerve block: a case report. Headache. 2018;58(1):154-156. doi:10.1111/head.13192

22. Stieber VW, Bourl JD, Ellis TL. Glossopharyngeal neuralgia treated with gamma knife surgery: treatment outcome and failure analysis. $J$ Neurosurg. 2005;102(supplement):155-157.

23. Shah RV, Racz GB. Pulsed mode radiofrequency lesioning to treat chronic post-tonsillectomy pain (secondary glossopharyngeal neuralgia). Pain Pract. 2003;3(3):232-237. doi:10.1046/j.15332500.2003.03028.x

24. Singh PM, Maya D, Mohan VK, et al. Analgesic efficacy and safety of medical therapy alone vs combined medical therapy and extraoral glossopharyngeal nerve block in glossopharyngeal neuralgia. Pain Med. 2013;14(1):93-102. doi:10.1111/pme.12001

25. Shin JH, Herrera SR, Eboli P, et al. Entrapment of the glossopharyngeal nerve in patients with Eagle syndrome: surgical technique and outcomes in a series of 5 patients. JNeurosurg. 2009;111:1226-1230.

26. Bean-Lijewski JD. Glossopharyngeal nerve block for pain relief after pediatric tonsillectomy: retrospective analysis and two cases of life-threatening upper airway obstruction from an interrupted trial. Anesth Analg. 1997;84(6):1232-1238. doi:10.1097/00000539-199706000-00011

27. Martínez-Álvarez R, Martínez-Moreno N, Kusak ME, Rey-Portolés G. Glossopharyngeal neuralgia and radiosurgery. $J$ Neurosurg. 2014;121(Suppl):222-225. doi:10.3171/2014.8.GKS141273

28. Nader A, Kendall MC, De Oliveria GS, et al. Ultrasound-guided trigeminal nerve block via the pterygopalatine fossa: an effective treatment for trigeminal neuralgia and atypical facial pain. Pain Physician. 2013;16(5):E537-E545.

29. Siegenthaler A, Haug M, Eichenberger U, et al. Block of the superior cervical ganglion, description of a novel ultrasound-guided technique in human cadavers. Pain Med. 2013;14(5):646-649. doi:10.1111/ pme. 12061

30. Narouze S. Ultrasound-guided stellate ganglion block: safety and efficacy. Curr Pain Headache Rep. 2014;18(6):424. doi:10.1007/ s11916-014-0424-5

31. Allam AE, Khalil AAF, Eltawab BA, et al. Ultrasound-guided intervention for treatment of trigeminal neuralgia: an updated review of anatomy and techniques. Pain Res Manag. 2018;2018:1-9. doi: $10.1155 / 2018 / 5480728$

32. Ozveren MF, Türe U. The microsurgical anatomy of the glossopharyngeal nerve with respect to the jugular foramen lesions. Neurosurg Focus. 2004;17(2):12-21. doi:10.3171/foc.2004.17.2.3

33. Myles PS, Urquhart N. The linearity of the visual analogue scale in patients with severe acute pain. Anaesth Intensive Care. 2005;33:5458. doi:10.1177/0310057X0503300108

34. De Loach LJ, Higgins MS, Caplan AB, Stiff JL. The visual analogue scale in the immediate postoperative period: intrasubject variability and correlation with a numeric scale. Anesth Analg. 1998;86:102-106. doi:10.1097/00000539199801000-00020 
35. Cepeda MS, Africano JM, Polo R, Alcala R, Carr D. What decline in pain intensity is meaningful to patients with acute pain? Pain. 2003;105:151-157.

36. Vanderpol J, Jonker L. Influence of patient positioning on reported clinical outcomes after greater occipital nerve block for treatment of headache: results from prospective single-centre, non-randomised, proof-of-concept study. Clin Neurol Neurosurg. 2019;176:73-77. doi:10.1016/j.clineuro.2018.12.001

37. Eker HE, Cok OY, Aribogan A, Arslan G. Management of neuropathic pain with methylprednisolone at the site of nerve injury. Pain Med. 2012;13:443-451. doi:10.1111/j.1526-4637.2011.01323.x
38. Stout A, Friedly J, Standaert CJ. Systemic absorption and side effects of locally injected glucocorticoids. Pm R. 2019;11:409-419. doi:10.1002/pmrj. 12042

39. Armstrong RD, English J, Gibson T, Chakraborty J, Marks V. Serum methylprednisolone levels following intra-articular injection of methylprednisolone acetate. Ann Rheum Dis. 1981;40:571-574. doi:10.1136/ard.40.6.571

40. Deer T, Ranson M, Kapural L, et al. Guidelines for the proper use of epidural steroid injections for the chronic pain patient. Tech Reg Anesth Pain Manag. 2009;13(4):0-295. doi:10.1053/j.trap.2009.06.010

\section{Publish your work in this journal}

The Journal of Pain Research is an international, peer reviewed, open access, online journal that welcomes laboratory and clinical findings in the fields of pain research and the prevention and management of pain. Original research, reviews, symposium reports, hypothesis formation and commentaries are all considered for publication. The manuscript management system is completely online and includes a very quick and fair peer-review system, which is all easy to use. Visit http:// www.dovepress.com/testimonials.php to read real quotes from published authors. 